\title{
Burden and profile of spinal pathology at a major tertiary hospital in the Western Cape, South Africa
}

\author{
Miseer $\mathrm{S}^{1} \mathbb{0}$, Mann $\mathrm{T}^{2} \mathbb{0}$, Davis $\mathrm{JH}^{3}$ \\ 1 MBChB, FC Orth (SA); Division of Orthopaedic Surgery, Department of Surgical Sciences, Faculty of Medicine and Health Sciences, Stellenbosch \\ University, Tygerberg Hospital, Cape Town, South Africa \\ 2 PhD; Division of Orthopaedic Surgery, Department of Surgical Sciences, Faculty of Medicine and Health Sciences, Stellenbosch University, \\ Cape Town, South Africa \\ 3 MBChB, MMed(Ortho), FC Orth (SA); Division of Orthopaedic Surgery, Department of Surgical Sciences, Faculty of Medicine and Health Sciences, \\ Stellenbosch University, Cape Town, South Africa
}

Corresponding author: Dr Sanesh Miseer, Tygerberg Hospital, Francie Van Zijl Drive, Cape Town, 7500, South Africa; Tygerberg Hospital, Private Bag X3 Tygerberg, 7505; tel: 021938 4911; email: saneshmsr@gmail.com

\begin{abstract}
Background: Spinal pathology in the Western Cape is managed at three tertiary level hospitals, including Tygerberg Hospital. The Tygerberg Hospital Orthopaedic Spinal Unit is responsible for the management of spinal pathology for the 3.4 million people in the hospital's catchment area. However, the unit's overall burden of disease and associated resource use is currently unclear.

Aim: The first aim was to investigate the overall burden and clinical profile of spinal pathology presenting to the Tygerberg Hospital Spinal Unit over a one-year period. The second aim was to determine resource use associated with spine pathology admissions.

Methods: Overall burden was investigated by performing a retrospective review of all patients admitted to the Spine Unit between 1 October 2016 and 30 September 2017. Demographic and clinical data was collected, and patients were assigned to one of five spinal pathology sub-groups. Resource use was determined by length of hospital stay, waiting times, advanced imaging and theatre usage.

Results: Overall burden comprised 349 individual patients and 376 admissions, including readmissions. Trauma (51\%) and infection (24\%) accounted for the majority of admitted pathology with degenerative (10\%), deformity $(7 \%)$ and malignancy $(7 \%)$ representing fewer admissions. Motor vehicle accidents were the primary mechanism of injury, accounting for $48 \%$ of spine trauma. Tuberculosis was the causative organism in $87 \%$ of spinal infections with $44 \%$ HIV co-infection. Hospital resource use was considerable with $92 \%$ of spine patients requiring advanced imaging, a median operating time of $3 \mathrm{~h} 36 \mathrm{~min}$ and a median hospital stay of 19 days. Infection and malignancy sub-groups had the longest waiting times for advanced imaging and theatre with a median wait of 14-16 days, accounting for approximately $62 \%$ of the typical total hospital stay.
\end{abstract}

Conclusions: The Spine Unit experienced a substantial patient burden requiring significant hospital resources. Reduced in-patient waiting times and upskilling of orthopaedic services at secondary hospitals represent key areas for health system strengthening. However, multi-sectoral strategies would be required to effectively address our high burden of largely preventable spinal pathology.

\section{Level of evidence: Level 4}

Key words: spinal pathology epidemiology, spinal trauma, spinal tuberculosis, spinal surgery

Citation: Miseer S, Mann T, Davis JH. Burden and profile of spinal pathology at a major tertiary hospital in the Western Cape, South Africa. SA Orthop $J$ 2019;18(1):33-39. http://dx.doi.org/10.17159/2309-8309/2019/v18n1a4

Editor: Prof RN Dunn, University of Cape Town, South Africa

Received: May 2018

Accepted: August 2018

Published: March 2019

Copyright: ( 2019 Miseer S. This is an open-access article distributed under the terms of the Creative Commons Attribution Licence, which permits unrestricted use, distribution and reproduction in any medium, provided the original author and source are credited.

Funding: No funding was received for this study.

Conflict of interest: The authors declare they have no conflicts of interest that are directly or indirectly related to the research. 


\section{Introduction}

Spinal pathology represents a wide spectrum of disease involving components of the Functional Spinal Unit and contents of the spinal canal. ${ }^{1}$ Typical spinal orthopaedic presentations can be broadly classified into trauma, infection, malignancy, degenerative and deformity subgroups, each of which involve a distinct diagnostic and management approach. Nevertheless, all types of spinal pathology can have major implications for functional ability and quality of life, hence access to appropriate treatment is of high importance. ${ }^{2,3}$

In the Western Cape, specialist spinal services are only available at three tertiary level hospitals, including Tygerberg Hospital. Officially opened in 1976, Tygerberg Hospital is the largest tertiary hospital in the province and the second largest in the country with 1384 active beds and an annual budget of R2.6 billion. ${ }^{4}$ Tygerberg Hospital's Orthopaedic Spinal Unit is responsible for the management of all spinal column pathology, including acute, nonpenetrating spinal cord injuries, for a population of 3.4 million within the hospital's catchment area. However, the unit is staffed by only one permanent and one sessional consultant, a long-term fellow and two orthopaedic registrars.

Anecdotal evidence suggests that the Spine Unit manages a significant volume of patients, many of whom require advanced imaging, considerable theatre time and a lengthy hospital stay. However, this has not been formally investigated, with previous burden of disease studies focusing on specific conditions such as spinal cord injury and spinal tuberculosis (TB). ${ }^{5-7}$ It follows that the overall profile of spinal pathology presenting to a tertiary institution in South Africa and the associated burden on health system resources is currently unclear.

With this in mind, the first aim of the current study was to investigate the overall burden and clinical profile of spinal pathology presenting to the Tygerberg Hospital Spinal Unit over a one-year period, including patient demographics and human immunodeficiency virus (HIV) prevalence within each pathology subgroup. The second aim of the study was to determine the resource use associated with spinal pathology admissions, including the length of hospital stay, use of advanced radiological modalities and theatre time. It is envisaged that increased insight into the volume, distribution and resource costs of spinal pathology within our setting will help to identify areas for health system strengthening, including accurate and adequate resource allocation.

\section{Materials and methods}

\section{Overall burden}

A retrospective review was performed of all patients admitted to the Spine Unit at Tygerberg Hospital during the period 1 October 2016 to 31 September 2017. Patients were initially identified from the admission files of the Unit's primary admitting wards, after which this list was cross-referenced with the principal investigator's personal surgical logbook to ensure that no surgical cases were unaccounted for. All duplicate cases were identified and removed.

\section{Demographic and clinical characteristics}

Patient case records, radiological and biochemical investigations were reviewed, and clinical and demographic information collected for each patient included age, sex, residential area, region of pathology and HIV status. Patients were also assigned to one of five spinal pathology subgroups based on clinical notes: trauma, deformity, degenerative disease, infection and malignancy.

Further information pertaining to the two most prevalent subgroups, trauma and infection, was also collected. Trauma data included the mechanism of injury (MOI), presence of polytrauma, and American Spinal Injury Association (ASIA) score on admission. Among patients with infection, the causative organisms were categorised as TB or 'other' and Frankel grade on admission was recorded.

\section{Resource use}

To determine the resource use per patient, the length of hospital stay, use of advanced radiological investigations, total theatre time, and waiting times for surgery and for advanced imaging were recorded. Theatre time was obtained from intra-operative records of the anaesthetic start and end times as recorded by a member of the nursing team.

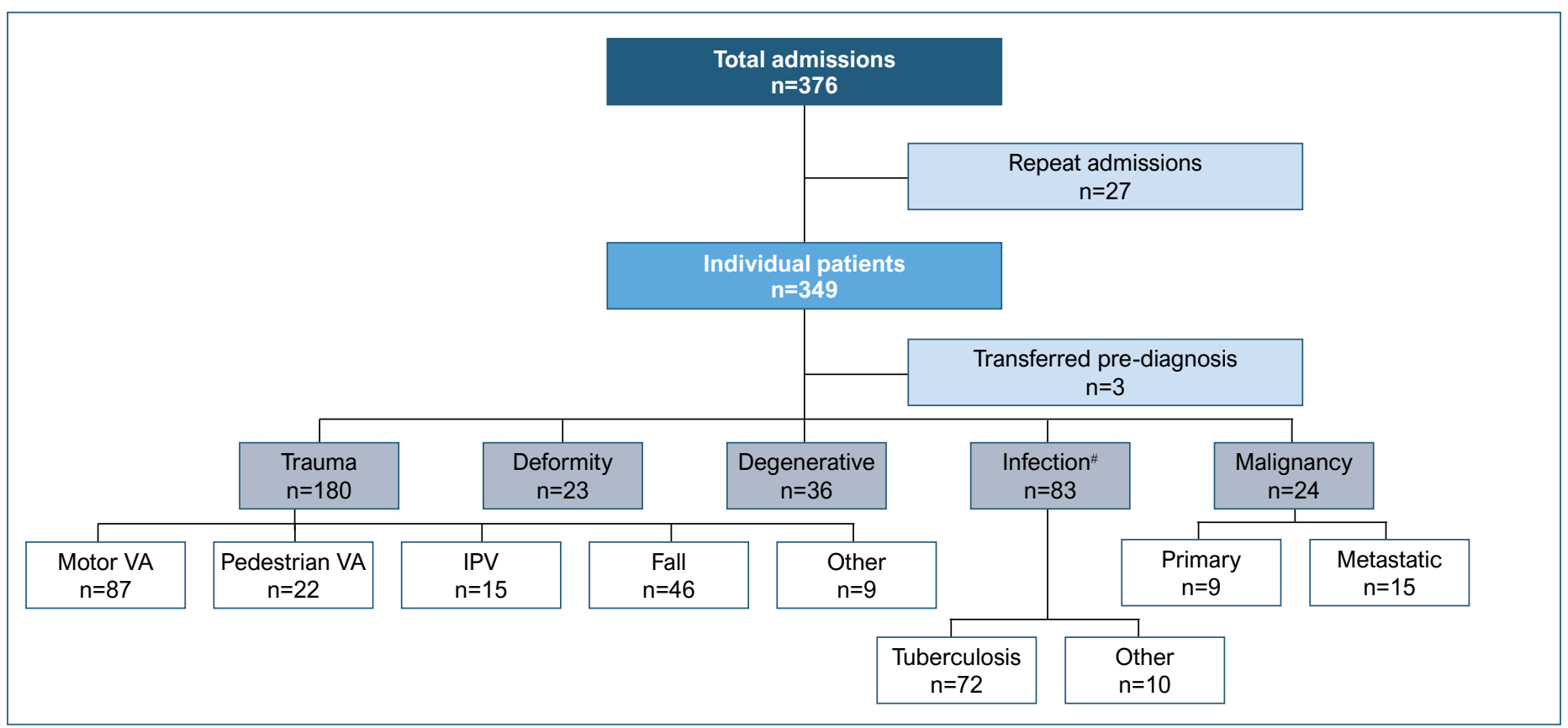

Figure 1. Absolute burden of patients admitted to Tygerberg Hospital Spinal Unit within a one-year period, in total and by pathology. VA = vehicle accident, IPV = inter-personal violence. *Mechanism of trauma, missing data $(n=1)$, \#Infection causative organism unknown ( $n=1)$ 


\section{Data analysis}

Categorical data was presented as counts and percentages whereas continuous data was tested for normal distribution and presented as mean \pm standard deviation (SD) or median and interquartile range (IQR) as appropriate. When continuous data was normally distributed within some pathology groups but not others, median (IQR) was presented for all groups. Statistical analysis was conducted using Microsoft Excel 2013 (๔ 2012 Microsoft Corporation, Impressa Systems, Santa Rosa, California) and Graphpad Prism (GraphPad Prism version 6.00, GraphPad Software, La Jolla, California).

\section{Ethical considerations}

The study was approved by the Human Research Ethics Committee of Stellenbosch University and by the management of Tygerberg Hospital.

\section{Results}

\section{Overall burden and clinical profile}

A total of 349 individual patients were admitted to the Spine Unit over the one-year study period (Figure 1). In addition to the initial admission, 21 (6\%) patients required one re-admission and three (<1\%) patients required two re-admissions, amounting to 376 admissions in total.

Trauma and infection made up the majority of admitted pathology, accounting for $75 \%$ of the overall burden (Figures 1 and 2 ). Among trauma admissions, a motor vehicle accident (MVA) was the primary $\mathrm{MOI}$, accounting for $48 \%$ of spinal trauma, with falls contributing a further $26 \%$. Polytrauma was noted in $39 \%$ of trauma patients with an MVA or pedestrian vehicle accident (PVA) recorded as the $\mathrm{MOI}$ in $65 \%$ and $24 \%$ of polytrauma cases, respectively. TB was the dominant causative organism among patients with infection, accounting for $87 \%$ of admissions in this subgroup.

\section{Demographic and clinical characteristics}

Patient clinical and demographic characteristics are shown in Table I. Overall, patients with spine pathology ranged from 1 to 80 years of age, including 29 children $\leq 14$ years old. Age distribution was distinctive within each subgroup, with the trauma and infection pathologies affecting a particularly wide range of ages (Figure 3). Although most pathology subgroups showed an approximately equal distribution of males and females, the trauma subgroup showed a notably higher proportion of male patients $(67 \%)$

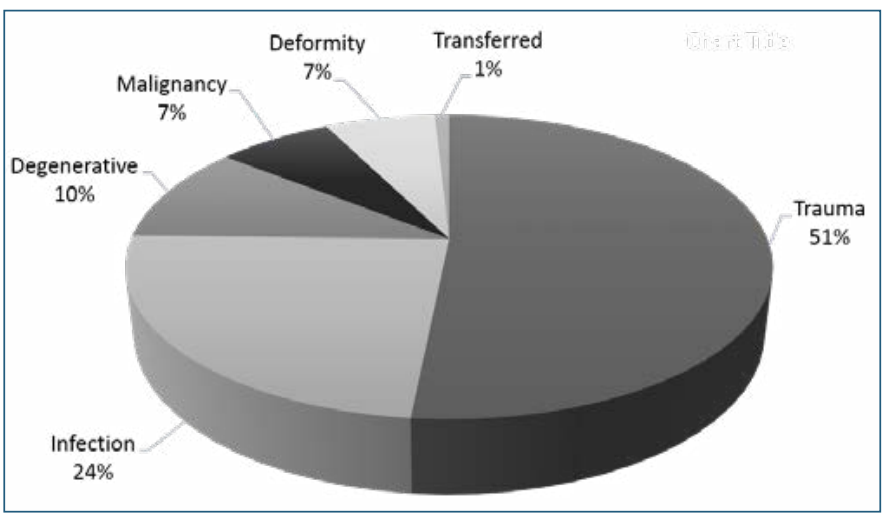

Figure 2. Distribution of pathology among Tygerberg Hospital Spinal Unit patients
(Table I). Overall, most spine patients were from the Cape Metro $(65 \%)$ or the Cape Winelands (18\%) with a much smaller contribution from the hospital's other referral districts.

While $17 \%$ of all spine patients were confirmed HIV positive, a further $58 \%$ had an unknown HIV status. Nevertheless, there was some variation in HIV testing between subgroups with HIV status known in $86 \%$ of the infection subgroup and only $17-46 \%$ of the other subgroups. Of the 72 patients with spinal TB, 32 (44\%) were HIV positive, 33 (46\%) HIV negative and seven (10\%) of unknown status.

Neurology was intact in $74 \%$ and $61 \%$ of spine trauma and infection patients, respectively, with only $4-5 \%$ presenting with complete paralysis. Notably, the majority ( 45 of 68 ) of patients with polytrauma presented as ASIA E.

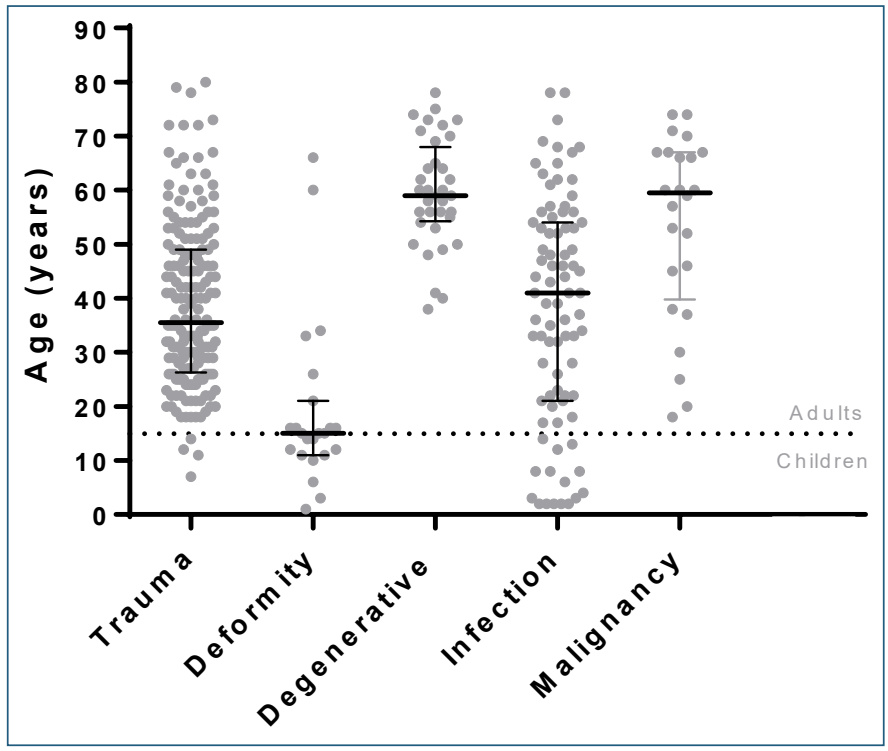

Figure 3. Age distribution within pathology type. Error bars indicate median and IQR

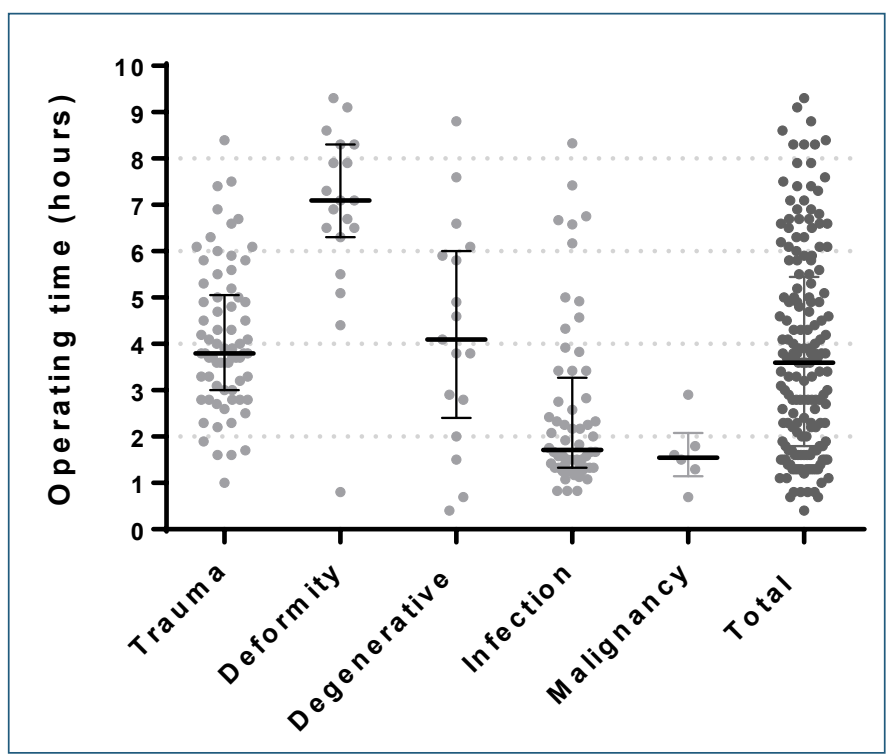

Figure 4. Operating time within pathology type. Error bars indicate median and IQR

Available operating times: trauma $(n=70)$, deformity $(n=19)$, degenerative $(n=17)$, infection $(n=60)$, malignancy $(n=6)$, total $(n=172)$ 
Table I: Demographic and clinical characteristics of Tygerberg Hospital Spinal Unit patients

\begin{tabular}{|c|c|c|c|c|c|c|}
\hline & $\begin{array}{l}\text { Trauma } \\
(n=180)\end{array}$ & $\begin{array}{l}\text { Deformity } \\
(n=23)\end{array}$ & $\begin{array}{c}\text { Degenerative } \\
\qquad(n=36)\end{array}$ & $\begin{array}{c}\text { Infection } \\
(n=83)\end{array}$ & $\begin{array}{l}\text { Malignancy } \\
(n=24)\end{array}$ & $\begin{array}{c}\text { Total } \\
(n=346)\end{array}$ \\
\hline \multicolumn{7}{|l|}{ Demographics } \\
\hline Age, median (IQR) & $36(26-49)$ & $15(11-21)$ & $59(54-68)$ & $41(21-54)$ & $60(40-67)$ & $41(26-56)$ \\
\hline Male sex, n (\%) & $121(67)$ & $10(43)$ & $20(56)$ & $40(48)$ & $12(50)$ & $203(59)$ \\
\hline \multicolumn{7}{|l|}{ District, n (\%) } \\
\hline City of Cape Town & $108(60)$ & $14(61)$ & $26(72)$ & $64(77)$ & $12(50)$ & $224(65)$ \\
\hline Cape Winelands & $34(19)$ & $6(26)$ & $6(17)$ & $13(16)$ & $5(21)$ & $64(18)$ \\
\hline Overberg & $16(9)$ & $1(4)$ & - & $6(7)$ & $5(21)$ & $28(8)$ \\
\hline West Coast & $20(11)$ & $1(4)$ & $4(11)$ & - & $2(8)$ & $27(8)$ \\
\hline Other & $2(1)$ & $1(4)$ & - & - & - & $3(1)$ \\
\hline \multicolumn{7}{|l|}{ HIV status, $n(\%)^{*}$} \\
\hline Positive & $19(11)$ & - & $1(3)$ & $35(42)$ & $4(17)$ & $59(17)$ \\
\hline Negative & $31(17)$ & $4(17)$ & $6(17)$ & $36(43)$ & $7(29)$ & $84(24)$ \\
\hline Unknown & $129(72)$ & $19(83)$ & $28(80)$ & $12(14)$ & $13(54)$ & $201(58)$ \\
\hline \multicolumn{7}{|c|}{ Vertebrae affected, n (\%) } \\
\hline Cervical & $85(47)$ & $2(9)$ & $11(31)$ & $1(1)$ & $3(13)$ & $102(29)$ \\
\hline Thoracic & $20(11)$ & $12(53)$ & $4(11)$ & $34(41)$ & $2(8)$ & $72(21)$ \\
\hline Thoracolumbar & $41(23)$ & $4(17)$ & - & $12(14)$ & $2(8)$ & $59(17)$ \\
\hline Lumbar & $14(8)$ & $2(9)$ & $11(31)$ & $24(29)$ & $2(8)$ & $53(15)$ \\
\hline Lumbosacral & $5(3)$ & $3(13)$ & $7(19)$ & $4(5)$ & $4(17)$ & $23(7)$ \\
\hline Non-contiguous & $15(8)$ & - & $3(8)$ & $8(10)$ & $11(46)$ & $37(11)$ \\
\hline \multicolumn{7}{|c|}{ ASIA/Frankel Grade, n (\%)† } \\
\hline A & $9(5)$ & $\mathrm{n} / \mathrm{a}$ & $\mathrm{n} / \mathrm{a}$ & $3(4)$ & $\mathrm{n} / \mathrm{a}$ & $12(5)$ \\
\hline B & $2(1)$ & $\mathrm{n} / \mathrm{a}$ & $\mathrm{n} / \mathrm{a}$ & $2(3)$ & $\mathrm{n} / \mathrm{a}$ & $4(2)$ \\
\hline C & $15(9)$ & $\mathrm{n} / \mathrm{a}$ & $\mathrm{n} / \mathrm{a}$ & $15(20)$ & $\mathrm{n} / \mathrm{a}$ & $30(12)$ \\
\hline D & $18(10)$ & $\mathrm{n} / \mathrm{a}$ & $\mathrm{n} / \mathrm{a}$ & $9(12)$ & $\mathrm{n} / \mathrm{a}$ & $27(11)$ \\
\hline$E$ & $128(74)$ & $\mathrm{n} / \mathrm{a}$ & $\mathrm{n} / \mathrm{a}$ & $46(61)$ & $\mathrm{n} / \mathrm{a}$ & $174(70)$ \\
\hline
\end{tabular}

*HIV status missing data, trauma $(n=1)$, degenerative $(n=1), \uparrow A S I A / F r a n k e l$ grade missing data, trauma $(n=8)$, infection $(n=8)$

\section{Resource use}

Hospital resource use associated with each initial Spine Unit admission is shown in Table II. Overall, 92\% of spine patients required some form of advanced imaging, with $26 \%$ receiving both a computed tomography (CT) and a magnetic resonance imaging (MRI) scan. In contrast to other subgroups, trauma patients were most likely to have an isolated CT scan (53\%) and accounted for $94 \%$ of patients receiving a CT scan only. The majority of patients in the deformity, degenerative and infection subgroups received an MRI scan only (57-82\%), whereas patients with malignancy required both $\mathrm{CT}$ and $\mathrm{MRI}$ imaging in $54 \%$ of cases.

Overall, $52 \%$ of spine patients received operative management, with the trauma and infection subgroups requiring surgery in $41 \%$ and $78 \%$ of patients, respectively (Table II). Although patients with malignancy utilised the largest percentage of combined imaging out of any subgroup while admitted to the unit, only $25 \%$ underwent surgery. Of the 346 patients for whom operative data was available, the median (IQR) operating time was $3 \mathrm{~h} 36 \mathrm{~min}(1 \mathrm{~h} 48 \mathrm{~min}$ to $5 \mathrm{~h} 27 \mathrm{~min}$ ). However operative time varied by subgroup with the shortest median (IQR) operative times recorded for malignancy (1 h $33 \mathrm{~min}, 1 \mathrm{~h} 09 \mathrm{~min}$ to $2 \mathrm{~h} 05 \mathrm{~min}$ ) and infection (1 h $43 \mathrm{~min}$, $1 \mathrm{~h} 20 \mathrm{~min}$ to $3 \mathrm{~h} 17 \mathrm{~min}$ ), and the longest for deformity ( $7 \mathrm{~h} 06 \mathrm{~min}$, $6 \mathrm{~h} 18 \mathrm{~min}$ to $8 \mathrm{~h} 18 \mathrm{~min}$ ) (Figure 4).

Median hospital stay varied by pathology, with the degenerative subgroup showing the shortest median stay (eight days) and the deformity subgroup the longest (38 days). Among patients with infection and malignancy, there was a median 14-16 day waiting time between admission and surgery, of which a median of 8-10 days was spent waiting for an MRI scan. It follows that waiting time for MRI and surgery typically accounted for more than $50 \%$ of the median total hospital stay of 23-25 days for these subgroups.

While the majority of patients from other subgroups were discharged home, $79 \%$ of patients with malignancy were transferred to another department within Tygerberg Hospital. Furthermore $17 \%$ of patient with infection were discharged to the Western Cape Rehabilitation Centre (WCRC), representing the most common discharge pathway for TB spine patients with neurological fallout. Only $3 \%$ of patients required referral to the Acute Spinal Cord Injury (ASCl) Unit at Groote Schuur Hospital with a further 3\% recorded as 'Other' discharge pathways such as deaths, patient refusal of hospital treatment and absconsions.

\section{Discussion}

\section{Burden and clinical profile}

The first finding of the study was that the Orthopaedic Spinal Unit at Tygerberg Hospital experienced a substantial patient burden over the one-year study period, including 349 individual patients and 376 separate admissions. The clinical profile of spine patients was dominated by trauma and infection, with these subgroups accounting for $51 \%$ and $24 \%$ of all spine pathology, respectively.

Spinal orthopaedic surgery is a highly specialised branch of Orthopaedics and its scope of practice in our centre is not limited 
Table II: Imaging, treatment, hospital stay and discharge pathway for Tygerberg Hospital Spinal Unit patients

\begin{tabular}{|c|c|c|c|c|c|c|}
\hline & $\begin{array}{l}\text { Trauma } \\
(n=180)\end{array}$ & $\begin{array}{l}\text { Deformity } \\
(n=23)\end{array}$ & $\begin{array}{l}\text { Degenerative } \\
(n=36)\end{array}$ & $\begin{array}{l}\text { Infection } \\
(n=83)\end{array}$ & $\begin{array}{l}\text { Malignancy } \\
(\mathrm{n}=24)\end{array}$ & $\begin{array}{c}\text { Total } \\
(n=346)\end{array}$ \\
\hline \multicolumn{7}{|l|}{ Advanced imaging, n (\%) } \\
\hline No advanced imaging & $15(8)$ & $1(4)$ & $4(11)$ & $6(7)$ & $1(4)$ & $27(8)$ \\
\hline CT only & $95(53)$ & - & $1(3)$ & $1(1)$ & $4(17)$ & $101(29)$ \\
\hline MRI only & $13(7)$ & $13(57)$ & $27(75)$ & $68(82)$ & $6(25)$ & $127(37)$ \\
\hline CT and MRI & $57(32)$ & $9(39)$ & $4(11)$ & $8(10)$ & $13(54)$ & $91(26)$ \\
\hline \multicolumn{7}{|l|}{ Treatment, n (\%) } \\
\hline Non-operative & $107(59)$ & $4(17)$ & $18(50)$ & $18(22)$ & $18(75)$ & $165(48)$ \\
\hline Operative & $73(41)$ & $19(83)$ & $18(50)$ & $65(78)$ & $6(25)$ & $181(52)$ \\
\hline \multicolumn{7}{|c|}{ Waiting time and hospital stay, days median (IQR) } \\
\hline Admission to $\mathrm{MRI}^{*}$ & $2(1-10)$ & $8(1-24)$ & $2(1-9)$ & $8(3-12)$ & $10(5-14)$ & $6(1-12)$ \\
\hline Admission to surgery & $6(3-11)$ & $3(3-17)$ & $3(3-8)$ & $14(9-22)$ & $16(8-23)$ & $8(3-17)$ \\
\hline Total hospital days & $15(9-27)$ & $38(18-60)$ & $8(4-16)$ & $25(19-36)$ & $23(18-30)$ & $19(10-31)$ \\
\hline \multicolumn{7}{|l|}{ Discharge pathway, n (\%) } \\
\hline Discharged home & $114(63)$ & $19(83)$ & $32(89)$ & $43(52)$ & $3(13)$ & $211(61)$ \\
\hline Discharged to WCRC & $15(8)$ & $3(13)$ & - & $14(17)$ & - & $32(9)$ \\
\hline Transferred to ASCl & $11(6)$ & - & - & - & - & $11(3)$ \\
\hline $\begin{array}{l}\text { Transferred to another TBH } \\
\text { department }\end{array}$ & $11(6)$ & $1(4)$ & $3(8)$ & $7(8)$ & $19(79)$ & $41(12)$ \\
\hline $\begin{array}{l}\text { Transferred to another } \\
\text { hospital }\end{array}$ & $26(14)$ & - & - & $15(18)$ & $1(4)$ & $42(12)$ \\
\hline Other & $3(2)$ & - & $1(3)$ & $4(5)$ & $1(4)$ & $9(3)$ \\
\hline
\end{tabular}

$\mathrm{CT}=$ computed tomography, $\mathrm{MRI}=$ magnetic resonance imaging, WCRC $=$ Western Cape Rehabilitation Centre, $\mathrm{ASCl}=$ Acute Spinal Cord Injury Unit $(\mathrm{Groote}$ Schuur Hospital), TBH = Tygerberg Hospital. *Data available for patients receiving in-patient MRIs: trauma $(n=64)$, deformity $(n=7)$, degenerative $(n=9)$, infection $(n=65)$, malignancy $(n=17)$, total $(n=162)$

by age or pathology type. Our varied clinical profile supports this, especially if one considers the admission of 29 paediatric patients which in itself is a significant burden given the added demands of this population group. The discipline is also predominantly consultant-driven with regard to decision-making and surgical management and includes the teaching of registrars and medical students. The high burden of spinal pathology in the state sector lacks adequate specialist cover and this is made even more apparent when compared to the private healthcare sector; a total of 26 private spinal orthopaedic surgeons currently listed on the South African Spine Society webpage ${ }^{8}$ for a population of 1.3 million medical aid members in the Western Cape, ${ }^{9}$ versus 1.5 surgeons for 3.4 million people.

To our knowledge, the current study was the first to report the clinical profile of spinal pathology presenting at a tertiary hospital in South Africa, including the major contribution of spinal trauma. Nevertheless, the high volume of trauma admissions is in keeping with the overall high trauma burden seen in South Africa. For example, there were over 50000 trauma-related deaths reported countrywide in $2015^{10}$ and injuries were purported to account for $20 \%$ of male deaths in the Cape Town Metro between 2010 and 2015. ${ }^{11}$

The majority $(60.5 \%)$ of spine trauma was caused by road traffic collisions, with $80 \%$ due to MVAs and the remainder to PVAs. The majority of MVA-related trauma illustrates the highenergy, acceleration/deceleration mechanisms required for spinal pathology. In contrast, a previous multicentre study assessing the burden of spine fractures in India reported that falls were the primary cause of injury in $72 \%$ of the patient group. Furthermore, traffic accidents accounted for only $23 \%$ of all spine fractures despite India having twice as many reported non-fatal road traffic injuries as South Africa. ${ }^{12,13}$ This contrast suggests that MVAs within our setting are particularly severe, a premise supported by a 2016 report ranking the Western Cape as the province with the third highest road traffic collision fatalities. ${ }^{14}$ Of concern is that causal analysis of fatal crashes shows that $74 \%$ are due to human factors, meaning that this massive burden is largely preventable. ${ }^{15}$

While the second largest subgroup of spinal pathology was broadly described as infection, $87 \%$ of these patients were individuals with spinal TB. It is well established that the Western Cape has one of the highest burdens of TB worldwide, with a reported incidence of 681 cases per $100000^{16}$ and a true incidence that is almost certainly higher. Within the Western Cape, the Cape Metro is the district with the highest absolute burden of $\mathrm{TB},{ }^{16}$ and this was also the district from which the majority $(77 \%)$ of our spinal infection patients presented. A higher burden of spinal TB in urban areas is in keeping with previous findings from KwaZulu-Natal ${ }^{7}$ and is likely explained by adverse living conditions.

Another well-known risk factor for TB is HIV infection and in the current study, $44 \%$ of patients with spinal TB were HIV-infected with a further $10 \%$ of unknown HIV status. This HIV prevalence is approximately twice as high as the $20 \%$ HIV prevalence reported among patients with spinal TB treated at Groote Schuur Hospital, a discrepancy that could possibly be explained by an increase in HIV prevalence in the Western Cape between the study periods (2013-2014 vs 2016-2017), ${ }^{17}$ more areas with high HIV prevalence within the Tygerberg catchment area, ${ }^{18}$ and differences in the number of individuals with unknown status (10\% vs $16 \%)$. More importantly, the current HIV prevalence was approximately four times the estimated national HIV prevalence of $12.6 \%$ and almost 
seven times the HIV prevalence in the Western Cape. ${ }^{19}$ While this appears to suggest an association between HIV-infection and spinal TB, evidence from prospective studies is required to confirm this link.

When considering that trauma and infection account for $75 \%$ of the burden on spine services at Tygerberg Hospital, it is pertinent to note that these pathology types are to some extent preventable. For example, stricter road traffic laws and harsher penalties for infringements may help to reduce the incidence of high velocity MVAs in the province, and ongoing efforts to reduce TB transmission may reduce the incidence of spinal TB. When excluding spine pathology due to MVAs, PVAs, inter-personal violence and spinal TB, the current patient burden is reduced by $56 \%$ from 349 to 153 patients - highlighting the extent of the preventable burden. While such drastic reductions are unrealistic, the current study could serve as a useful baseline with which to audit relevant societal interventions in the future.

\section{Resource use}

The second finding of the current study was that spine pathology was a significant consumer of hospital resources with $92 \%$ of patients requiring advanced imaging, a median operating time of $3 \mathrm{~h} 36 \mathrm{~min}$ and a median hospital stay of 19 days. While relatively high resource consumption for managing spine pathology may be well known anecdotally, to our knowledge the current study is one of the first to formally quantify this.

High utilisation of key resources such as scanners, operating theatres and hospital beds has implications not only for hospital services but also on the expenses incurred. For example, according to current cash prices in the private sector, the average cost of a regional spinal CT and MRI is R3 600 and R6 400, respectively.

Using the aforementioned estimates, the total cost of diagnostic imaging for isolated CTs in $53 \%$ of the trauma subgroup was R342 000 . The infection subgroup required the greatest number of isolated MRIs due to the modality's value with management, and incurred a total cost of R1 305600 for $24 \%$ of all spine patients. Exact costing for imaging modalities in the state sector was difficult to obtain and while the cost analysis of the different subgroups is crude, it does provide insight into the significant potential expenditure.

A further key expense associated with managing spinal pathologies is theatre time. Theatre time is one of the most valuable resources in the health system and is estimated to cost R10 300 per hour. ${ }^{20}$ Spinal surgery is generally lengthier given the complexities of both anaesthesia and surgery and is best reflected in our deformity cases which averaged just over seven hours at a cost of roughly R72 000 per case for theatre time alone. Our biggest burdens of trauma and infection averaged a total theatre cost of R35 000 and R15 000, respectively. The relatively short theatre usage for the infection subgroup demonstrates the large number of pedicle biopsies performed in order to establish a tissue diagnosis. ${ }^{21,22}$

Overall, only $52 \%$ of spine patients received operative management, indicating the unit's appreciation for its resourcelimited environment and ability to appropriately treat certain pathologies non-operatively. Nevertheless, further cost-saving could be achieved by appointing a dedicated, experienced spinal anaesthetic team to lower anaesthetic time and thus overall surgical time. Furthermore, improved provision of basic spinal surgical services at district level would allow for simpler procedures, such as biopsy-taking, to be conducted in secondary hospitals where theatre time is cheaper. ${ }^{23}$

While advanced imaging and frequent operative treatment are implicit in managing spinal pathology, the high associated costs are compounded by inpatient waiting times for these modalities. Due to the severity of pathology referred to the Spine Unit, the opportunities for outpatient advanced imaging are rare with the majority of patients either draining directly to Tygerberg Hospital with no secondary holding facility or requiring the immediate care and expertise of a specialised unit. Outpatient MRI waiting times are also longer as priority is given to inpatients, and very often admitting patients is the most efficient way of providing timely treatment. Although trauma waiting times were impressive considering the overall burden of trauma presenting to Tygerberg Hospital, typical waiting time from admission to surgery was approximately two weeks in the infection and malignancy subgroups. As a result, waiting times contributed substantially to the longer total hospital stay of 23-25 days in the infection and malignancy subgroups.

The average cost of a tertiary level general ward hospital stay is $\mathrm{R} 1640$ per day for the facility alone, ${ }^{23}$ resulting in a total cost of R31 160 for the average spine patient, with the longer hospital stays averaging R62 320. When one considers the average waiting time of 14 days from admission to surgery for the infection patient, a total facility cost of R22 960 is incurred per patient purely from 'waiting' for advanced imaging and theatre. This is more expensive than a whole spine MRI and stresses the need for not only increased, but efficient MRI and surgical theatre services to meet this enormous burden.

Just as most of the burden of spine pathology seen at the Tygerberg Hospital Spinal Unit is preventable, so too could the high costs of treating these preventable conditions be theoretically averted. With a minimum total cost for a surgically treated trauma or infective patient ranging from R62 000 to R68 000, it is clear that both policymakers and society need to be held more accountable before the monetary impact of the disease burden becomes unbearable.

While long-term goals of reduced trauma and infection will require time and multi-sector cooperation to achieve, short- and mediumterm goals for saving costs and strengthening health systems could include innovative strategies to reduce the cost of inpatient waiting times at tertiary level and upskilling of basic spinal services at the district level. Given the consultant-driven nature of spinal surgery, it is inferred that further training and employment of sub-specialists will improve service delivery and lower overall costs, especially when faced with the high burden of spinal pathology demonstrated in our study.

\section{Conclusion}

Our study is the first to describe admissions to a tertiary spinal unit in the South African setting and demonstrated a large patient burden and a clinical profile dominated by preventable pathologies such as MVAs and spinal TB. The study was also one of the first to quantify resource use between spine pathologies and to confirm the high resource cost of spine pathology management. The high burden of preventable, costly spine pathology within our resource-limited environment highlights a need for urgent, multisectoral interventions. However, health system interventions such as reduced inpatient waiting time and upskilling of orthopaedic services at secondary hospitals would also be very beneficial. Future research could focus on the effectiveness of such strategies on the burden, clinical profile and resource use associated with spinal pathology.

\section{Ethics statement}

The study was approved by the Human Research Ethics Committee of Stellenbosch University and by the management of Tygerberg Hospital.

All procedures were in accordance with the ethical standards of the institutional and/ or national research committee and with the 1964 Helsinki declaration and its later 
amendments or comparable ethical standards. A waiver of informed consent was granted for this retrospective review.

\section{Declaration}

The authors declare authorship of this article and that they have followed sound scientific research practice. This research is original and does not transgress plagiarism policies.

\section{Acknowledgements}

The authors would like to thank Mr Danie Krynauw for his valuable contribution to data collection for the study.

\section{Author contributions}

SM contributed to the original study concept, proposal write-up, data collection and analysis, and final article write-up.

TM contributed to the original study concept, data analysis, and assisted with the article and proposal write-up.

JD contributed to the study design, layout and final article concepts.

\section{ORCID}

Miseer S (D) http://orcid.org/0000-0003-0478-0668

Mann T (iD https://orcid.org/0000-0002-9750-5106

Davis JH (D) http://orcid.org/0000-0002-1909-7629

\section{References}

1. White and M. Panjabi A. Clinical Biomechanics of the Spine, 2nd ed. Philadelphia: Lippincott 1990;2:18-20.

2. Mancuso CA, Stal M, Duculan R, Girardi FP. Physical and psychological comorbidity independently associated with spine-related disability. Spine (Phila. Pa. 1976). 2014;39:1969-74.

3. Otani K, Kikuchi S, Yabuki S, Igarashi T, Nikaido T, Watanabe K, et al. Lumbar spinal stenosis has a negative impact on quality of life compared with other comorbidities: An epidemiological cross-sectional study of 1862 community-dwelling individuals. Sci. World J. 2013;2013.

4. Western Cape Government. Tygerberg Hospital Facts and Figures. Tygerb. Hosp. Inf. Pam. 2016;6-7. Available from: https://www. westerncape.gov.za/your_gov/153

5. Joseph C, Delcarme A, Vlok I, Wahman K, Phillips J, Nilsson Wikmar L. Incidence and aetiology of traumatic spinal cord injury in Cape Town, South Africa: A prospective, population-based study. Spinal Cord 2015;53:692-96. Available from: http://dx.doi. org/10.1038/sc.2015.51

6. Held MFG, Hoppe S, Laubscher M, Mears S, Dix-Peek S, Zar HJ et al. Epidemiology of musculoskeletal tuberculosis in an area with high disease prevalence. Asian Spine J. 2017;11:405-11.

7. Godlwana L, Gounden P, Ngubo P, Nsibande T, Nyawo K, Puckree $\mathrm{T}$. Incidence and profile of spinal tuberculosis in patients at the only public hospital admitting such patients in KwaZulu-Natal. Spinal Cord 2008;46:372-74.

8. The South African Spine Society. No title. Available from: http:// www.saspine.org/

9. Barron P, Padarath A South African Health Review 2017. 2017. Available from: url: http://www.hst.org.za/publications/ south-african-health-review-2017

10. Statistics South Africa. Mortality and causes of death in South Africa, 2015: Findings from death notification. Stat. release P0309.3 2016;1-127. Available from: http://www.statssa.gov.za/ publications/P03093/P030932015.pdf\%0Ahttp://www.statssa.gov. za/Publications/P03093/P030932010.pdf\%5Cnhttp://www.statssa. gov.za/Publications/P03093/P030932009.pdf

11. Massyn N, Padarath A, Peer N DC. District Health Barometer 2016/2017. Durban: Health Systems Trust; 2017.

12. Aleem IS, DeMarco D, Drew B, Sancheti P, Shetty V, Dhillon M et al. The burden of spine fractures in India: A prospective multicenter study. Glob. Spine J. 2017;7:325-33.

13. Toroyan T. Global status report on road safety. World Health Organization. 2009;15:286-86.

14. Gainewe M. Road Traffic Manag. Corp. 2016 Calendar Year Rep. Available from: http://www.rtmc.co.za/images/doc/Calender/ Calender2016/Calendar 2016 report

15. Republic of South Africa. National Road Safety Strategy 2016-2030. 2016;51. Available from: https://www.westerncape. gov.za/assets/departments/transport-public-works/Documents/ 2017_05_18_strategic_plans_national_road_safety_strategy_2016_ to_2030_approved.pdf

16. Massyn N, Peer N, Padarath A, Barron P, Day C, Trust HS, et al. District Health Barometer 2015/16. 2016.

17. Johnson LF, Dorrington RE, Moolla H. HIV epidemic drivers in South Africa: A model-based evaluation of factors accounting for inter-provincial differences in HIV prevalence and incidence trends. South. Afr. J. HIV Med. 2017;18:1-9. Available from: http:// www.sajhivmed.org.za/index.php/hivmed/article/view/695

18. Thom A. W Cape plots HIV rates by district. The South African Health News Service 2004 Oct;1-2.

19. Poolman M, van der Walt N, Luwaca B. Western Cape Prov AIDS Council. West. Cape Gov. 2017. Available from: http://sanac.org.za/ wp-content/uploads/2017/06/Western-Cape.pdf

20. Netcare Group. Netcare private hospitals Netcare day clinics. 2016;Available from: http://www.netcarehospitals.co.za/Portals/3/ Images/Content-images/PDF/Final-Netcare-RSA-Ind-Priv-PayingPatients.pdf

21. Dunn R, Zondagh I. Spinal tuberculosis: Diagnostic biopsy is mandatory. South African Med. J. 2008;98:360-66.

22. Watt JP, Davis JH. Percutaneous core needle biopsies: The yield in spinal tuberculosis. South African Med. J. 2014;104:29-32.

23. Western Cape Government. UPFS Billing Proced. Sched. Full-Paying Patients.Available from: https://www.westerncape. gov.za/general-publication/western-cape-government-hospital -tariffs-overview 